\title{
IDENTIFICATION, EXPRESSION IN E. COLI AND INSECT CELLS OF THE NON-STRUCTURAL PROTEIN NS2 ENCODED BY MRNA2 OF BOVINE CORONAVIRUS (BCV)
}

\author{
P. Boireau ${ }^{1}$, M.F. Madelaine ${ }^{2}$, D. Saulnier ${ }^{1}$, \\ J. Laporte ${ }^{2}$ and J.F. Vautherot ${ }^{2}$
}

${ }^{1}$ CNEVA-Laboratoire Central de Recherches Vétérinaires, 22 rue $\mathrm{P}$. Curie 94703 Maisons-Alfort cedex, France and 2 INRA-Unité de Virologie et Immunologie Moléculaires, C. R. J. J.-Domaine de Vilvert, 78352 Jouy en Josas cedex, France

\begin{abstract}
The coding part of mRNA 2 (ORF2) of BCV (F15 strain) was cloned and sequenced. The comparison of our sequence data with the sequence of the same ORF of BCV Quebec strain previously published revealed a major difference in the length of the C-terminal part of the NS2 protein. In vitro transcription and translation of ORF2 resulted in the synthesis of a single protein migrating with a $\mathrm{Mr}$ of $31 \mathrm{kDa}$. The ORF2 was fused in frame with the glutathione $\mathrm{S}$ transferase gene (GSH) in the pGEX vector. The fusion protein was synthezised as inclusion bodies which were concentrated and used to raise a monospecific antiserum. Alternatively the fusion protein was solubilized, purified by affinity chromatography and cleaved with Factor Xa to yield pure recombinant NS2. The ORF2 was also expressed in the baculovirus system and the recombinant proteins expressed in pro- and eukaryotic systems were compared on the basis of their size and immunoreactivity. Immunoprecipitation performed with the monospecific antiserum allowed us to identify NS2 in HRT18 infected cells, to follow its kinetic of synthesis, and to ascertain that NS2 was not incorporated in the virion as a minor structural component.
\end{abstract}

\section{INTRODUCTION}

Bovine coronavirus (BCV), an enteric coronavirus, causes acute enteritis in newborn calves and chronic infection in adult cattle. The genome of the BCV (F15 strain) is a positive stranded RNA of approximately 32 kilobases that encodes at least 4 structural proteins (1). The electrophoresis of uridine tritiated polyA RNA extracted from BCV infected HRT 18 cells followed by autoradiography revealed 8 different molecular mass species viral RNA(2, C. Crucières \& J Laporte, personnal communication). Partial nucleotide sequence of BCV F15 strain has been determined and the sizes of BCV mRNA that were deduced from the location of the consensus junction sequence CC/TAAAC corresponded to the experimental data (3). The mRNA 3, 4, 7 and 8 have been shown to encode the four structural proteins: Hemagglutinin-esterase (HE), Spike (S), Membrane (M) and Nucleocapsid (N) $(3,4,5,6)$. The messengers RNA5 and 6 code for minor protein of 12 and $9.8 \mathrm{kDa}$ respectively (7). The messenger RNA2 of BCV Quebec strain has been shown to code for a phosphoprotein of $32 \mathrm{kDa}(\mathrm{NS} 2)(8,9)$, but the function of this protein remains to be determined. We reported here the cloning, sequencing and expression in E. coli and insect cells of the ORF2 of BCV F15. The use of recombinant protein expressed in bacteria allowed us to elicit specific polyclonal antibodies and to purify NS2 protein. 


\section{RESULTS}

\section{CLONING AND SEQUENCING OF ORF2 OF BCV F15}

We obtained a cDNA library of BCV F15 using primer 532 as described $(3,4)$.We isolated and sequenced a clone encompassing the 5' proximal ORF of BCV mRNA2 (NS22) with two other overlapping cDNA clones (Fig 1). The 3' end of ORF2 had already been identified close to the start codon of the HE gene (3). The potential junction sequence ACTAAC of mRNA2 was found just upstream the first ATG codon which is in a strong context according to Kozack (10). These data indicated that BCV F15 genome contains an ORF homologous to the BCV Quebec ORF2 (8). Northern blot analysis of viral mRNA using NS22 and $4 \mathrm{~d} 67$ as probes, suggested that ORF2 gene is transcribed by mRNA2. The nucleotide sequence of $4 \mathrm{~d} 67$ and NS22 inserts upstream ORF2 shared 56\% homology with the 3 ' end of the polymerase gene of MHV-A59 genome (11).

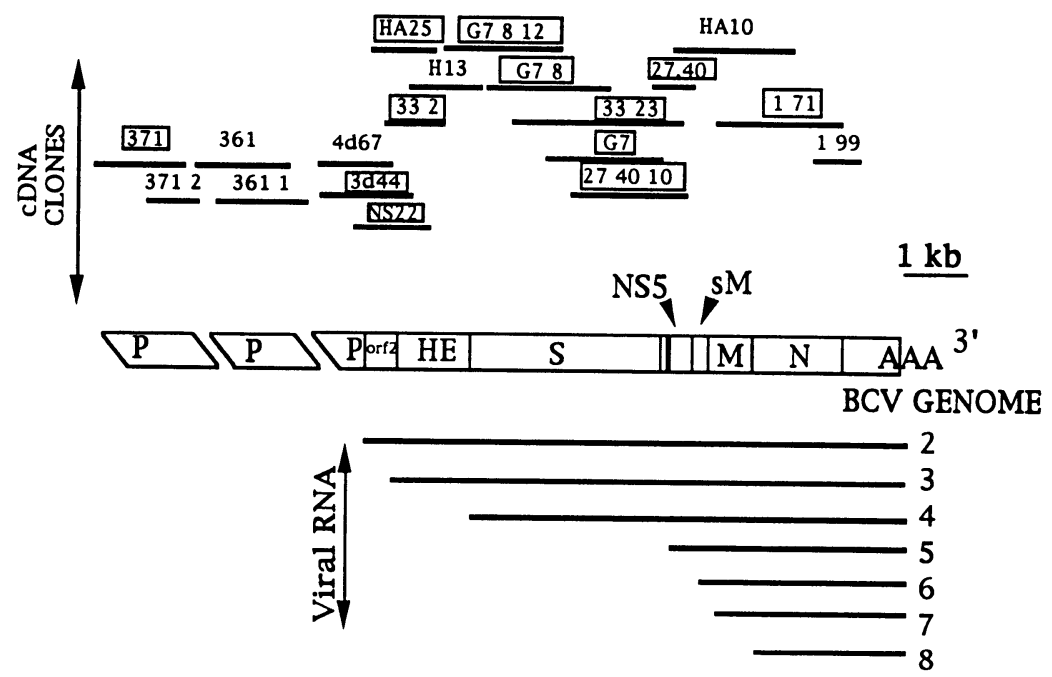

Figure 1. Cloning strategy for BCV F15 genome. Horizontal lines represent the relevant cDNA clones.The sequenced clones are boxed and the 7 subgenomic mRNA are shown under the BCV genome map.

\section{EXPRESSION OF ORF2 GENE IN VITRO}

The full length ORF2 was extracted from NS22 using Pst II and then submitted to a digestion with the Bal 31 nuclease (Stratagene) as described (13). The resulting insert was purified, cloned into pT3T7 plasmid (Pharmacia), thus yielding the p18U NS2 construct containing the ORF2 of BCV genome downstream the T7 promoter. We performed cell free transcription and translation of these transcripts in rabbit reticulocyte lysates (Promega). A unique $31 \mathrm{kDa}$ protein (Fig 2, lane5) was obtained, confirming the initiation at the first ATG codon.

\section{EXPRESSION OF ORF2 GENE IN BACTERIA}

We used two fusion protein vectors to express the full length ORF2 of BCV in E. coli. We first chose the pUEX vectors (14) to direct the synthesis of a cro-ßgal-NS2 protein migrating with a $\mathrm{Mr}$ of $146 \mathrm{kDa}$. 
The recombinant blotted protein $(15,16)$ was neither recognized by a serum of rabbit immunized with BCV purified virions nor by a serum of a convalescent young calf inoculated with BCV. As we failed to induce specific antibodies against NS2 protein with the cro-ßggalNS2 protein, we used the pGEX vector(17) which directs the synthesis of polypeptide in $E$. coli as fusion with the $\mathrm{C}$-terminal part of glutathion $\mathrm{S}$ transferase. The resulting recombinant peptide can be purified by affinity chromatography on glutathion agarose beads. Factor Xa can cleave the GST from the recombinant fusion protein. The pGEX-ORF2 construct was transfected into $E$. coli strain NM522 where expression of the fusion protein was triggered by addition of $1 \mathrm{mM}$ IPTG in the cell culture. Following expression and cell lysis GST-NS2 fusion protein was examined by SDS-PAGE electrophoresis. The analysis revealed a major band at the expected $\mathrm{Mr}$ of $57 \mathrm{kDa}$ which was not present in the control preparation. The fusion protein was synthesized to high level and accumulated in an insoluble form.

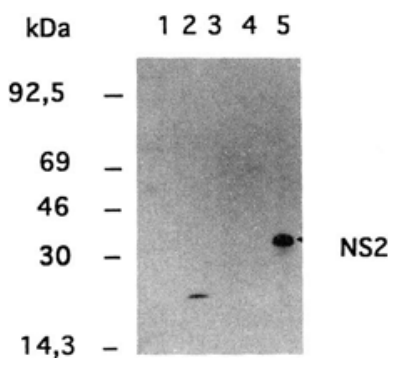

Figure 2. Cell free translation of mRNAs synthetized in vitro from p18UNS2 construct. Two ug of each of these mRNAs were used to proceed the translation in the presence of ( $35 \mathrm{~S}$ ) methionine and a rabbit reticulocyte lysate. The products were analysed on a 8-20\% polyacrylamide gel .Lane1: molecular weight ; Lane 2: BMV m RNA ; Lane 3 : negatif control ; Lane 4 : internal control ; Lane 5 : NS2 mRNA.

\section{SOLUBILISATION AND PURIFICATION OF NS2 EXPRESSED IN BACTERIA}

Inclusion bodies containing GST-NS2 recombinant protein were washed with $2 \mathrm{M}$ urea in PBS in order to eliminate low Mr bacterial proteins. The GST-NS2 protein was then dissolved into $7.5 \mathrm{M}$ guanidine chloride (18) and dialysed against four buffer changes of progressively decreasing the molarity of urea in PBS. We obtained a soluble GST-NS2 (Fig 3 ) which was purified with glutathion agarose beads (SIGMA). The purified fusion protein was cleaved with the factor Xa into GST (26kDa) and NS2 (31kDa) (Fig. 3). The NS2 protein was easily recovered by centrifugation of the agarose beads.

\section{OBTENTION OF SPECIFIC ANTI-NS2 POLYSERA}

Mice were immunized by injecting intraperitoneally concentrated GST-NS2 emulsified in Freund's complete adjuvant. These antisera immunoprecipitated a $31 \mathrm{kDa}$ protein from BCV F15 infected HRT 18 cells (Fig.4a) and recognized the purified recombinant protein by Western blot analysis (preimmune antisera failed to react with NS2). The NS2 protein expressed in Sf9 cells using a baculovirus vector was also immunoprecipitated, thus confirming the specificity of the anti-NS2 sera (Fig.4b). We were not able to immunoprecipitate NS2 protein from purified radiolabelled virions; this result together with 
the absence of reactivity of different anti-BCV polysera against NS2 indicated that this viral encoded protein is a nonstructural protein.

We determined the kinetics of synthesis of the NS2 protein in HRT 18 cells. NS2 appears as soon as $5 \mathrm{~h}$ post infection in the same time as the other structural proteins. The synthesis of NS2 continued until the end of the viral cycle.

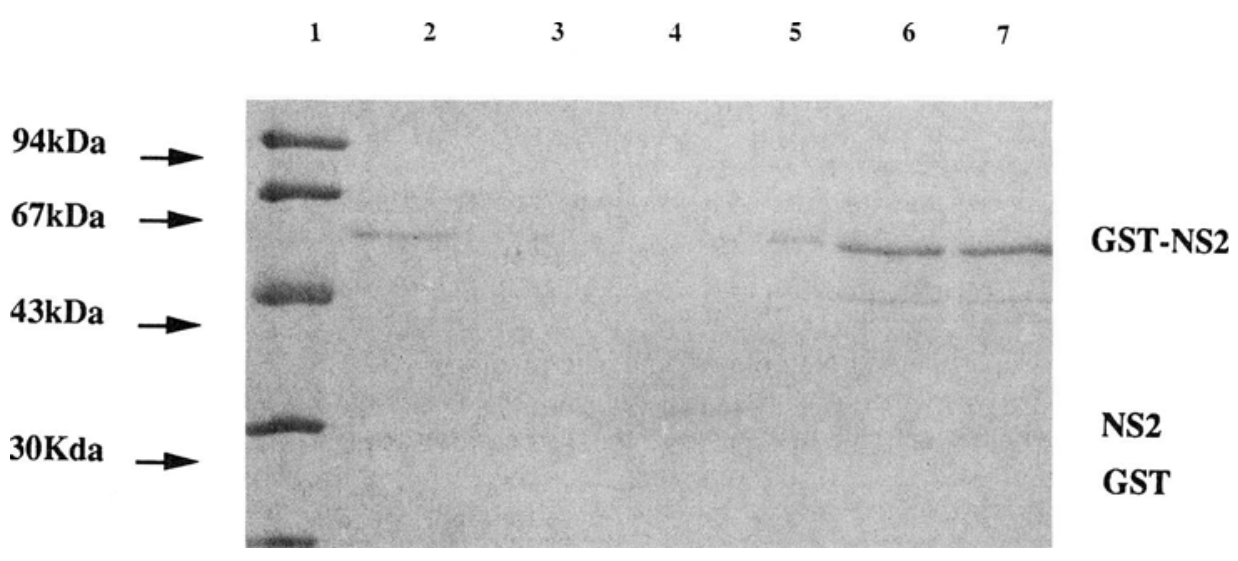

Figure 3. Cleavage of the GST-NS2 protein by Xa protease and purification of NS2. Lane 1: Molecular weight. Lane 2: GST-NS2 digested with Xa protease (1hour incubation at room temperature). Lanes 3 \& 4: The GST-NS2 protein was purified by glutathion agarose beads after fixation of GST-NS2 and digestion with Xa protease.

\section{DISCUSSION}

These results enabled us to achieve the description of the genomic organisation of the BCV F15 strain, dowstream the polymerase gene. We can deduce the gene sequence of the BCV F15 genome from 5' to 3'end as: Pol-NS2-HE-S-NS5-sM-M-N. The study presented here confirmed that mRNA2 code for a protein of $30,5 \mathrm{kDa}(\mathrm{NS} 2)(8)$. The predicted polypeptide of BCV F15 strain shares $97 \%$ homology with the corresponding protein of BCV Quebec strain (8). We could observe a difference in length at the $C$ terminal part of the NS2 protein between the two BCV isolates, resulting from 3 additions (A $784 \& 826, C 823$ ) and 1 deletion (T 782, (8)) in BCV F15 strain. A striking feature is the existence of heterologous recombination in MHV A59 in the same part of the genome. A potential variability in this part of the BCV and MHV genomes with recombination, deletion/insertion, indicates another hot spot region in the coronavirus genomes.

No characteristics signatures was found in NS2 aa sequence except one potentiel glycosylation site and three potential phosphorylation sites. Comparison of our sequence data with those from the homologuous proteins of two MHV strains $(19,20)$ did not reveal any known conserved motif.

We failed at detecting the BCV F15 mRNA2 product, a $31 \mathrm{kDa}$ Mr protein, as a structural protein embedded into virions.

The NS2 protein was synthesised in the same time as the other structural proteins (M, $\mathrm{HE}, \mathrm{S}, \mathrm{N}$ ), but at a lower rate, possibly reflecting a lower concentration in mRNA2 in infected cells(2). The kinetics of synthesis of NS2 in infected HRT18 cell line appeared slightly different by comparison with the previously published kinetic of NS2 in infected MDBK cell line. The peak of NS2 synthesis occured quickly after the beginning of the viral protein synthesis (7-8 h p.i.). We observed a marked accumulation of NS2 protein $24 \mathrm{~h}$ p.i.[as described (9)] but the increasing amount of NS2 reflected the occurence of a second viral cycle. So, as described for MHV (21), NS2 is expressed continuously during viral infection. We did not observe a NS2 processing similar to that of HE and $S$ and the immunoreactivity of the recombinant protein expressed in insect cell was not modified. 

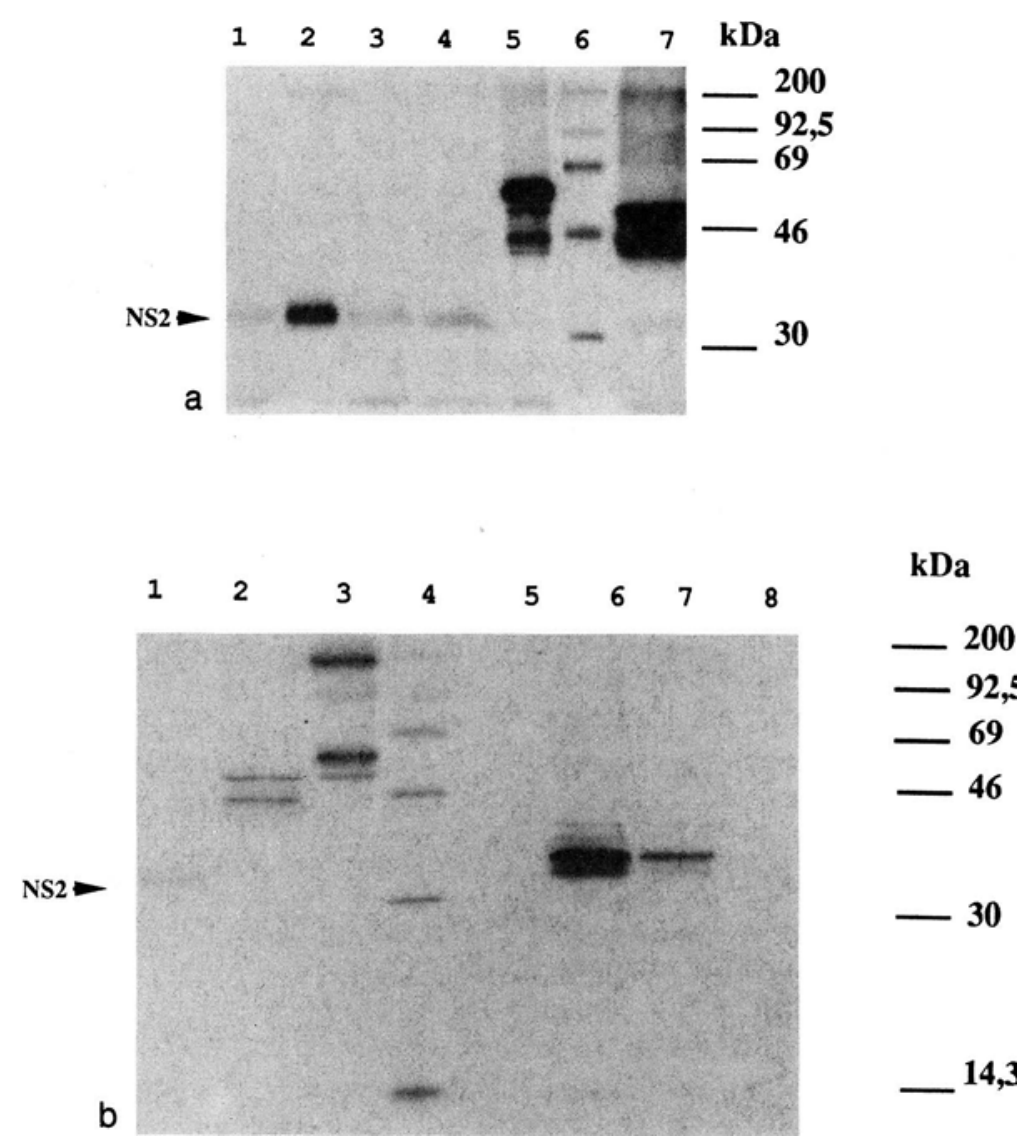

Figure 4a. Immunoprecipitations of the NS2 protein from radiolabelled BCV F15 infected cells lysates. Lanes 1, 2, 3, 4: Immunoprecipitations with four different polyclonal sera of mice immunised with GST-NS2 protein. Lane 5: Immunoprecipitation of $\mathrm{HE}$ protein with the monoclonal antibody J17b(16). Lane 6: Molecular weight markers. Lane 7: Negative control: immunoprecipitation with non immune mice serum.

4b. Immunoprecipitation of the the recombinant NS2 protein expressed in insect cells.

Lane 1: Immunoprecipitation of NS2 protein from BCV infected cell lysate. Lane 2: Negative control: immunoprecipitation of BCV infected cell lysate with non immune mice serum. Lane 3: Immunoprecipitation of $\mathrm{HE}$ protein with the monoclonal antibody $\mathrm{J} 17 \mathrm{~b}(16)$. Lanes 6 \& 7: Immunoprecipitations of the recombinant NS2 protein expressed in insect cells. Lane 8: Negative control: immunoprecipitation of a recombinant $\mathrm{SM}$ baculovirus infected cells with anti-NS2 serum.

\section{REFERENCES}

1. Laporte, J. \& Bobulesco, P., (1981), "Biochemistry and Biology of Coronaviruses",. V. ter Meulen, S. Siddel and H. Wege eds, pp 181-184, Plenum Publishing Corp., New-York

2. Keck, J.G, Hogue, B.G., Brian, D.A. \& Lai, M.M.C. (1988).Virus Res., 9, 343356.

3. Boireau P., Woloszyn N., Crucière C., Savoysky E., Laporte J. (1990a). In: "Coronaviruses and their diseases", D. Cavanagh and D. Brown eds, pp 81-88.

4. Boireau P., Crucière C., Laporte J. (1990b). J. Gen. Virol., 71, 487-492.

5. Savoysky E., Boireau P., Finance C., Laporte J. (1990). Res. Virol., 141, 411-425.

6. Crucière, C. \& Laporte, J. (1988). Ann. Virol. (Inst. Pasteur), 139, 123-138.

7. Woloszyn N., Boireau P., Laporte J. (1990).Nucl. Ac. Res. 18, 1303.

8. Cox, G.J., Parker, M.D. \& Babiuk, L.A. (1989). Nucleic Acids Res., 17(14), 5847.

9. Cox, G.J., Parker, M.D. \& Babiuk, L.A. (1991). Virology, 185, 509-512. 
10. Kozak, M. (1987). J. Mol. Biol., 196, 947-950.

11. Pachuk, C.J., Bredenbeck, P.J., Zoltick, P.W., Spaan, W.J.M. \& Weiss, S.R. (1989). Virology, 171, 141-148.

12. Cavanagh, D., Brian, D.A., Enjuanes, L., Holmes, K.V., Lai, M.M.C., Laude, H., Siddell, S.G., Spaan, W.J.M., Taguchi, F., \& Talbot, P.J. (1990).Virology, 176, 306-307.

13. Sambrook, J., Fritsch, E.F. \& Maniatis, T. (1989). Cold Spring Harbor Laboratory, Cold Spring Harbor, N.Y.

14. Bressan, G.M. \& Stanley, K.K. (1987). Nucleic Acids Res., 15(23), 10056.

15. Vautherot J.F., Laporte J., Boireau P.(1992). J. Gen. Virol.,.73, 1725-1737

16. Vautherot, J.F., Madelaine, M.F., Laporte, J. (1990). "Coronaviruses and their Diseases" (Cavanagh \& Brown, Eds), pp 173-180.Plenum Publishing Corp., NewYork.

17. Smith, D.B. \& Johnson, K.S. (1988). Gene, 67, 31-40.

18. Lefèvre, F., L'Haridon, Borras-Cuesta, F. \& La Bonnardière, C. (1990)). J. Gen. Virol., 71, 1057-1063.

19. Shieh, C-K., Lee, H-J., Yokomori, K., La Monica, N., Makino, S. \& Lai, M.M.C. (1989). J. Virol., 63, 3729-3736.

20. Luytjes, W., Bredenbeek, P.J., Noten, A.F.H., Horzinek, M.C. \& Spaan, W.J.M. (1988). Virology, 166, 415-422.

21. Bredenbeek, P.J., Noten, A.F.H., Horzinek, M.C. \& Spaan, W.J.M. (1989). Virology, 175, 303-306. 